\title{
Importance of species abundance for assessment of trait composition: an example based on pollinator communities
}

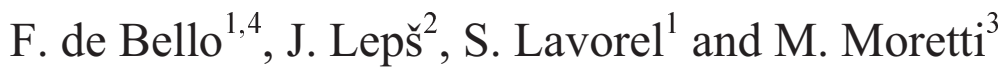 \\ ${ }^{1}$ Laboratoire d'Ecologie Alpine, CNRS UMR 5553, Université Joseph Fourier, F-38041, Grenoble, France \\ ${ }^{2}$ Department of Botany, Faculty of Science, University of South Bohemia, and Institute of Entomology, \\ Czech Academy of Sciences, CZ-37005, České Budějovice, Czech Republic \\ ${ }^{3}$ Swiss Federal Research Institute WSL, Ecosystem Boundaries Research Unit, Insubric Ecosystems Group, \\ CH-6500 Bellinzona, Switzerland \\ ${ }^{4}$ Corresponding author. Email: fradebello@ctfc.es
}

Keywords: Bee, Biodiversity, Community assembly, Dominant and rare species, Fire, Functional trait, Redundancy.

\begin{abstract}
Measurements of trait community composition are known to be sensitive to the way species abundance is assessed, but not to what extent. This was investigated by considering two of the most commonly used indices of community trait composition, trait averages and functional diversity, in bee communities along a post-fire environmental gradient. The indices were computed using three different species abundance measurements (log and unlog number of individuals and species occurrence only) and 5 traits. For certain traits, the responses of the indices to fire varied according to how species abundance was measured. The measurements that took species abundance into account in the most distinct way (e.g., occurrence vs. unlog data) produced the least similar results for all traits. Species were then grouped into different classes on the basis of their relative abundance (i.e., dominants, subdominants, and rare species). As a result, the measure that attaches the highest importance to the abundance of species (unlog data) related mostly to the dominant species traits, while the measure attaching the lowest (i.e., species occurrence) related more to rare species traits. Species diversity was mostly independent of trait averages and functional diversity, regardless of the measure of species abundance used. We also quantified functional redundancy (i.e., the potential minus the observed functional diversity in each community). When more weight was attached to species abundance, redundancy decreased and tended to be less correlated with species diversity. Overall, the way species abundance is taken into consideration in indices of functional composition offers promising insights into the way community assembly mechanisms respond to environmental changes.
\end{abstract}

Abbreviations: FD - Functional Diversity; ITD - Inter-Tegula Distance; log/unlog - Species abundance based on number of individuals with or without logarithmic transformation.

\section{Introduction}

The functional trait composition in a community is likely to be the most relevant biotic factor affecting ecosystem functioning (Diaz et al. 2007). In particular, environmental drivers select for or against species bearing certain traits, resulting in functional composition shifts with consequent feedbacks to ecosystem functioning (Garnier et al. 2004, Diaz et al. 2007). Variations in functional trait composition have often been described quantitatively by calculating two traditional indices: (a) trait averages over a community and/or (b) trait dissimilarity (Functional Diversity/Dissimilarity, FD). The trait average provides an indication of the most common traits in a community, while the FD indicates to what extent the species within a community are different in their traits (Lepš et al. 2006) and, thus for example, how the species share the niche space available (Mason et al. 2005, de Bello et al. 2006).

From a practical point of view, it is important to know whether such indices are very sensitive to the way the abundance of the species in a community is considered, or not (Ackerly et al. 2002, Garnier et al. 2004, Petchey and Gaston 2006, Lepš et al. 2006, Lavorel et al. 2008). These indices are usually calculated either taking into account species abundance (by 'weighting' the trait values of individual species in a given sample by species abundances) or without considering species abundance ('unweighting', taking into account only species occurrence). If species abundance is considered, it can be estimated in several ways (Magurran 2004): by counting individuals (population density; common in faunistic studies), or by 
Table 1. Abundance of species in the data set and division of the species into three categories of dominance.

\begin{tabular}{lcccc}
\hline $\begin{array}{l}\text { Categories of } \\
\text { dominance }\end{array}$ & $\begin{array}{c}\text { Number of } \\
\text { species }\end{array}$ & $\begin{array}{c}\text { Number of } \\
\text { individuals }\end{array}$ & $\begin{array}{c}\text { Relative } \\
\text { abundance per } \\
\text { species }\end{array}$ & $\begin{array}{c}\text { Relative } \\
\text { contribution per } \\
\text { group }\end{array}$ \\
\hline Dominant & 3 & 20028 & $>10 \%$ & $51 \%$ \\
Subdominant & 22 & 17134 & from 0.5 to $10 \%$ & $44 \%$ \\
Rare & 120 & 2035 & $<0.5 \%$ & $5 \%$ \\
Total & 145 & 39197 & & \\
\hline
\end{tabular}

estimating the frequency, cover or biomass (common in vegetation studies). Such measures, moreover, are often further transformed (e.g., log transformation) in order to reduce the weight of very abundant species, particularly in studies of animals. In vegetation studies, it is well known that the way species abundance is taken into account can lead to markedly different results (van der Maarel 1979, Lepš and Hadincová 1992). It has been hypothesized also that the indices of functional diversity, in particular, relate differently to species diversity indices depending on how species abundance is taken into account (Petchey and Gaston 2006).

According to the way species abundance is considered, a different importance will be attached to the dominant or less dominant species in a community (van der Maarel 1979, Ackerly et al. 2002, Magurran 2004, Cingolani et al. 2007). For example, a measure that treats species abundance as important will be mostly dependent on dominants, while a measure that considers only species occurrence (presence/absence data only) will attach the same weight to all species (Kafer and Witte 2004). Most natural and semi-natural communities have a common structure with few very abundant species, and many are only fairly frequent. The majority is, however, rare (e.g., Table 1; Novotny and Basset 2000, Magurran 2004). This pattern is repeated across a wide range of community types and different ecosystems with relatively little variation and can be correspondingly predicted with various Importance-Value distribution models (Whittaker 1970). Community structure also seems to be important to ensure ecological resilience in response to changing environmental conditions (Peterson et al. 1998, Walker et al. 1999).

The aim of this study was, therefore, to assess: (a) whether and to what extent different indices of trait composition are sensitive to the way species abundance is taken into account (i.e., in terms of logs, unlogs, or species occurrence); (b) assuming they are sensitive, how strongly the indices calculated with different species abundances reflect the traits of different classes of dominance in a community (i.e., dominant, subdominat and rare species); and (c) whether the relationship between indices of trait composition and species diversity indices changes with different measures of species abundance.
Secondly, we propose another potential index of community composition (together with the classical indices of trait averages and functional diversity), namely functional redundancy (i.e., the saturation in functionally similar species in a community). A lower variation in ecosystem processes is expected in more functionally redundant communities (Naeem 1998). Despite the importance of this trait composition property, the mathematical quantifications of redundancy have not, to our knowledge, been attempted yet.

For this study, we assessed several bee communities in areas under different fire regimes in chestnut stands in southern Switzerland. We focused on invertebrates (i.e., bees) because they have been less studied than plants in terms of functional traits and because it is easier with animals to use species abundance based on the counts of individuals (to give the highest weights to dominant species). Bees are widely used in ecological studies on ecosystem function (pollination; Kremer et al. 2007), their taxonomy is stable and functional traits are well known.

\section{Methods}

\section{Data set}

Bees were sampled in 21 study sites along a uniform south-facing slope (450-850 $\mathrm{m}$ above sea level) near Locarno $\left(46^{\circ} 09^{\prime} \mathrm{N}, 08^{\circ} 44^{\prime} \mathrm{E}\right)$ in southern Switzerland, using window traps (three per site, placed $1.5 \mathrm{~m}$ above ground) combined with yellow pans traps. The traps were emptied weekly from March to September 1997. The sites were grouped into four categories with respect to the time elapsed since the last fire: less than 1 year (2 sites), 2-3 years ( 3 sites), 6-17 years ( 7 sites), 20-24 years ( 3 sites) and not burned in the previous 30 years ( 6 sites). For more details, see Moretti et al. (2004, 2006).

All adult bees were identified to species. Specimens of each species are deposited at the Natural History Museum in Lugano (Switzerland). Each species was then described in terms of 5 functional traits: tongue length (short vs long), sociality status (solitary bees, social or with variable behavior), flight season start (month), voltinism (number of generations per year, i.e., univoltine, bivoltine or multivoltine) and inter-tegula distance (ITD, distance 
Table 2. Effects of considering different measures of species abundance (only species occurrence, $\log / \mathrm{unlog}$ transformed number of individuals) on indices of functional composition (trait average and functional diversity). Comparison 'i': correlation between indices calculated for each of 21 sites with all species (the minimum and maximum Pearson $r$ coefficients $\bar{\equiv}$ shown together with the number of significant correlations, $p<0.05$, over the 5 traits, i.e., $\mathrm{N}^{0}$ traits $/ 5$ ). Comparisons 'ii, and iv': correlation between indices calculated for all species with dominants, subdominants and rare species traits. Comparison ' $v$ ': correlations between different classes of dominance. Numbers in bold refer to the highest number of significant correlations for each comparison. The complete correlation results are given in the Appendix.

\begin{tabular}{|c|c|c|c|c|c|}
\hline \multirow[b]{2}{*}{ Comparison } & & \multicolumn{2}{|c|}{ Trait average } & \multicolumn{2}{|c|}{ Functional diversity } \\
\hline & & $\begin{array}{l}\text { Pearson } r \\
(\min / \max )\end{array}$ & $\begin{array}{l}\text { № traits } / 5 \\
\quad p<0.05\end{array}$ & $\begin{array}{l}\text { Pearson } r \\
(\min / \max )\end{array}$ & $\begin{array}{c}\mathrm{N}^{0} \\
\text { traits/5 } \\
p<0.05\end{array}$ \\
\hline \multirow{3}{*}{$\begin{array}{l}\text { i. Between indices } \\
\text { with all species }\end{array}$} & occurrence vs log & $0.51 / 0.91$ & 5 & $0.50 / 0.94$ & 5 \\
\hline & log vs unlog & $0.62 / 0.87$ & 5 & $0.58 / 0.83$ & 5 \\
\hline & occurrence vs unlog & $0.08 / 0.83$ & 3 & $0.04 / 0.58$ & 4 \\
\hline \multirow[t]{3}{*}{ ii. Dominants } & all species (occurrence) & $0.12 / 0.75$ & 2 & $0.06 / 0.60$ & 1 \\
\hline & all species (log) & $0.29 / 0.71$ & 3 & $0.02 / 0.94$ & 2 \\
\hline & all species (unlog) & $0.61 / 0.82$ & 5 & $0.49 / 0.93$ & 5 \\
\hline \multirow[t]{3}{*}{ iii. Subdominants } & all species (occurrence) & $0.12 / 0.63$ & 3 & $0.12 / 0.64$ & 2 \\
\hline & all species (log) & $0.69 / 0.83$ & 5 & $0.32 / 0.81$ & 4 \\
\hline & all species (unlog) & $0.16 / 0.78$ & 3 & $-0.07 / 0.78$ & 2 \\
\hline \multirow[t]{3}{*}{ iv. Rare } & all species (occurrence) & $0.82 / 0.94$ & 5 & $0.14 / 0.92$ & 4 \\
\hline & all species $(\log )$ & $0.50 / 0.92$ & 5 & $0.06 / 0.88$ & 4 \\
\hline & all species (unlog) & $-0.01 / 0.86$ & 4 & $-0.18 / 0.58$ & 3 \\
\hline \multirow[t]{3}{*}{ v. Between classes } & rare vs dominants & $-0.10 / 0.81$ & 3 & $-0.10 / 0.41$ & 0 \\
\hline & $\begin{array}{l}\text { subdomin. vs } \\
\text { dominants }\end{array}$ & $-0.35 / 0.37$ & 0 & $-0.31 / 0.37$ & 0 \\
\hline & rare vs subdominants & $0.06 / 0.58$ & 1 & $0.06 / 0.55$ & 1 \\
\hline
\end{tabular}

between the two insertion points of the wing). All traits were treated as semi-quantitative variable and scaled between zero and one, where zero represented the minimum value for that traits in the data set and one the maximum value (for traits with three categories, for example, we coded $0,0.5$ and 1$)$. The selected traits reflect important strategies for bees to cope with variations in habitat conditions and resource distribution thus resulting in different functions in the ecosystem (Biesmeijer et al. 2006, Kremer et al. 2007). Data were taken from published sources or from information obtained from experts (where published information for a particular species was not available). Species were then divided into three classes, similar to those in Mühlenberg (1993), according to their relative abundance in the whole data set: dominants $>$ $10 \%$, subdominants $0.5-10 \%$, and rare $<0.5 \%$ (Table 1 ).

\section{Data analysis}

For each site, trait averages and functional diversity (FD) were calculated. Both indices were calculated at four different levels of organization (Table 1) considering: (i) all species; (ii) only the 'dominant' species (from 1 to 4 species per site, 3 over the total data set); (iii) only the 'subdominant' species (from 12 to 26 per site, 22 over the total data set); and (iv) only the most 'rare' species (from 15 to 74 per site, 120 over the total set). For each trait we then calculated the Pearson correlation between the indi- ces estimated with the different methods (comparisons iiv, see Table 2 and the Appendix).

The trait average for each site was calculated as:

$\bar{x}=\sum_{i=1}^{s} p_{i} x_{i}$

with $p_{i}$ the proportion of $i$-th species in a sample, $s$ is the number of species in the community and $x_{i}$ the trait value of the $i$-th species (for the species occurrence data, $p_{i}$ is 1 divided by the number of species in that sample; also where indices were calculated on the basis of subgroups of species, $p_{i}$ was the proportion within the subgroup).

The FD index, a generalization of Rao's (1982) quadratic entropy index of diversity, was calculated as the sum of trait dissimilarities between pairs of species, multiplied by species abundance. If the proportion of $i$-th species in a community is $p_{i}$ and the dissimilarity between species $i$ and $j$ is $d_{i j}$, then FD has the form:

$$
F D=\sum_{i=1}^{s} \sum_{j=1}^{s} d_{i j} p_{i} p_{j}
$$

where $d_{i j}$ varies from 0 (i.e., where two species have exactly the same traits) to 1 (i.e., where the two species have completely different traits). For quantitative traits, $d_{i j}=$ 0.6 would indicate that species $i$ and $j$ are $60 \%$ functionally dissimilar. The dissimilarity was calculated as the dif- 
Table 3. Pearson correlation $(r)$ between indices of trait composition (trait average, functional diversity and redundancy) and indices of species diversity (richness, i.e., the number of species, and the Simpson index). All indices were calculated with different measures of species abundance. Numbers in bold indicate significant $(p<0.05)$ correlation

\begin{tabular}{|c|c|c|c|c|}
\hline Trait & Index & $\begin{array}{l}\text { Abundance } \\
\text { measure }\end{array}$ & Richness & Simpson \\
\hline \multirow{9}{*}{ Flying start } & \multirow{3}{*}{ Average } & presence & 0.75 & 0.71 \\
\hline & & $\log$ & 0.57 & 0.16 \\
\hline & & unlog & 0.19 & 0.15 \\
\hline & \multirow{3}{*}{ FD } & presence & 0.58 & 0.57 \\
\hline & & $\log$ & 0.41 & 0.10 \\
\hline & & unlog & -0.33 & 0.02 \\
\hline & \multirow{3}{*}{ Redund. } & presence & -0.46 & -0.43 \\
\hline & & $\log$ & -0.11 & 0.97 \\
\hline & & unlog & 0.19 & 0.44 \\
\hline \multirow{9}{*}{ ITD } & \multirow{3}{*}{ Average } & presence & -0.48 & -0.39 \\
\hline & & $\log$ & -0.50 & 0.11 \\
\hline & & unlog & -0.32 & -0.13 \\
\hline & \multirow{3}{*}{ FD } & presence & -0.26 & -0.21 \\
\hline & & $\log$ & -0.40 & -0.07 \\
\hline & & unlog & -0.11 & 0.07 \\
\hline & \multirow{3}{*}{ Redund. } & presence & 0.42 & 0.39 \\
\hline & & $\log$ & 0.08 & 0.98 \\
\hline & & unlog & 0.38 & 0.38 \\
\hline \multirow{9}{*}{ Sociality } & \multirow{3}{*}{ Average } & presence & -0.84 & -0.81 \\
\hline & & $\log$ & -0.66 & -0.01 \\
\hline & & unlog & -0.21 & 0.00 \\
\hline & \multirow{3}{*}{ FD } & presence & -0.87 & -0.83 \\
\hline & & $\log$ & -0.70 & -0.05 \\
\hline & & unlog & -0.27 & -0.07 \\
\hline & \multirow{3}{*}{ Redund. } & presence & 0.88 & 0.85 \\
\hline & & $\log$ & 0.29 & 0.91 \\
\hline & & unlog & 0.29 & 0.24 \\
\hline \multirow{9}{*}{$\begin{array}{l}\text { Tongue } \\
\text { length }\end{array}$} & \multirow{3}{*}{ Average } & presence & -0.28 & -0.18 \\
\hline & & $\log$ & -0.41 & -0.30 \\
\hline & & unlog & -0.26 & -0.07 \\
\hline & \multirow{3}{*}{ FD } & presence & -0.27 & -0.14 \\
\hline & & $\log$ & -0.42 & -0.33 \\
\hline & & unlog & -0.35 & -0.20 \\
\hline & \multirow{3}{*}{ Redund. } & presence & 0.37 & 0.25 \\
\hline & & $\log$ & 0.15 & 0.93 \\
\hline & & unlog & 0.36 & 0.34 \\
\hline \multirow{9}{*}{ Voltinism } & \multirow{3}{*}{ Average } & presence & -0.25 & -0.48 \\
\hline & & $\log$ & -0.08 & -0.22 \\
\hline & & unlog & -0.07 & -0.19 \\
\hline & \multirow{3}{*}{ FD } & presence & -0.24 & -0.47 \\
\hline & & $\log$ & -0.07 & -0.23 \\
\hline & & unlog & -0.15 & -0.13 \\
\hline & \multirow{3}{*}{ Redund. } & presence & 0.32 & 0.55 \\
\hline & & $\log$ & 0.02 & 0.92 \\
\hline & & unlog & 0.18 & 0.32 \\
\hline
\end{tabular}

ference in the trait value between two species. For example, if the trait is ITD and we have two species with ITD equal to 0.35 and 0.75 (all traits were scaled between zero and one, see above), the dissimilarity is 0.4 . Further details about the calculation of species dissimilarities by traits and about the macro file can be found in: http://botanika.bf.jc.cz/suspa/FunctDiv.php.

This index of functional diversity is a functional generalization of the popular Simpson index of species diversity (Botta-Dukát 2005, Lepš et al. 2006). In fact, if $d_{i j}=1$ for all pairs of species, then FD is identical to the Simpson index of diversity (see Botta-Dukát 2005, for details). The Simpson index, as a result, represents the maximum potential value FD can reach in a given community where the species functionally differ completely. Since in natural communities species are rarely completely functionally different (de Bello et al. 2006, Petchey and Gaston 2006), there is always a certain degree of functional redundancy (Naeem 1998).

Traditionally, redundancy has been defined as the number of species within a functional group (with more species implying more redundancy; Naeem 1998). Alternatively, it could be defined as how much a community is 'saturated' with species with similar traits. Such saturation depends on the relationship between species and functional diversity (Petchey and Gaston 2006; i.e., how much functional diversity increases with species diversity). In this case, redundancy could be calculated as the difference between the Simpson index of species diversity and the FD index (Redundancy $=\mathrm{SD}-\mathrm{FD}$; i.e., the potential FD minus the observed FD). If FD equals SD because all the species are functionally different, then redundancy is zero. If FD is zero because all the species are functionally identical, then redundancy is at a maximum and equal to the Simpson index of species diversity.

Therefore, we calculated the trait averages, the functional diversity and the redundancy for each community using three different species abundance measurements (log and unlog number of individuals, species occurrence only) and for the 5 traits. The Pearson correlations of these indices with species richness and with the Simpson index of species diversity were then assessed. Since the differences between the Simpson index and FD are based on the same measures of species abundance, we made sure that we did not correlate redundancy with the Simpson index with different species abundance measurements (Table 3). For the same reasons and because redundancy depends on both FD and the Simspon index, the comparisons given in Table 2 are presented only for trait averages and FD.

\section{Results}

The functional composition of the bee communities showed a more or less marked response to fire, depending on the measures of species abundance used (example given in Fig. 1). For both trait averages and FD, the most marked discrepancies were noted between the measurements that considered species abundance in the most distinct way (e.g., occurrence vs. unlog data), which also produced the least correlated values (Table 2). The indices of functional composition calculated with different 
measures of species abundance often produced significantly correlated results ('between indices with all species', see Table 2) even though pair-wise comparisons indicated that the absolute values could be different within each trait (Paired samples t-tests; not shown). All non-significant comparisons were observed between occurrence $v s$. unlog data (see appendix for details), which also had the lowest correlation (Pearson $r$ ) compared to the other two (occurrence $v s$. log and $\log v s$. unlog data).

The way species abundance is measured in assessing the indices of trait composition (averages and FD) can reflect the traits of dominant or less dominant species in a community. Overall, the measures that most magnify the difference in the abundance among species (e.g., unlog) give more weight to the dominant species traits ('domi- nants vs. all-unlog', Table 2). Conversely, the measure that treats all species as having the same abundance (i.e., species occurrence) relates more to rare species traits ('rare vs. all species occurrence', Table 2). Subdominants related mostly to $\log$ transformed measures.

Overall, trait average and functional diversity indices were poorly correlated with species richness and Simpson index of species diversity. It is thus difficult to observe whether the correlation changes if species abundance is weighted differently (Table 3 ). For given traits (i.e., sociality), we also observed significant negative correlations. Redundancy, on the other hand, was frequently positively correlated with the Simpson index of diversity (as a result of its formulation), and was the clearest correlation with log transformed data (Table 3).
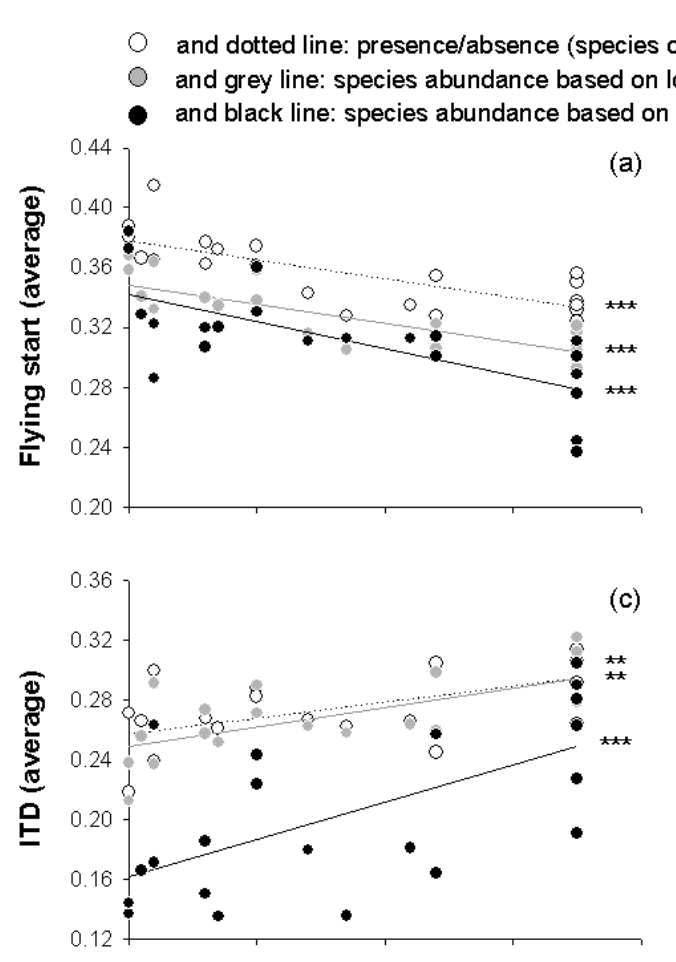

(c)
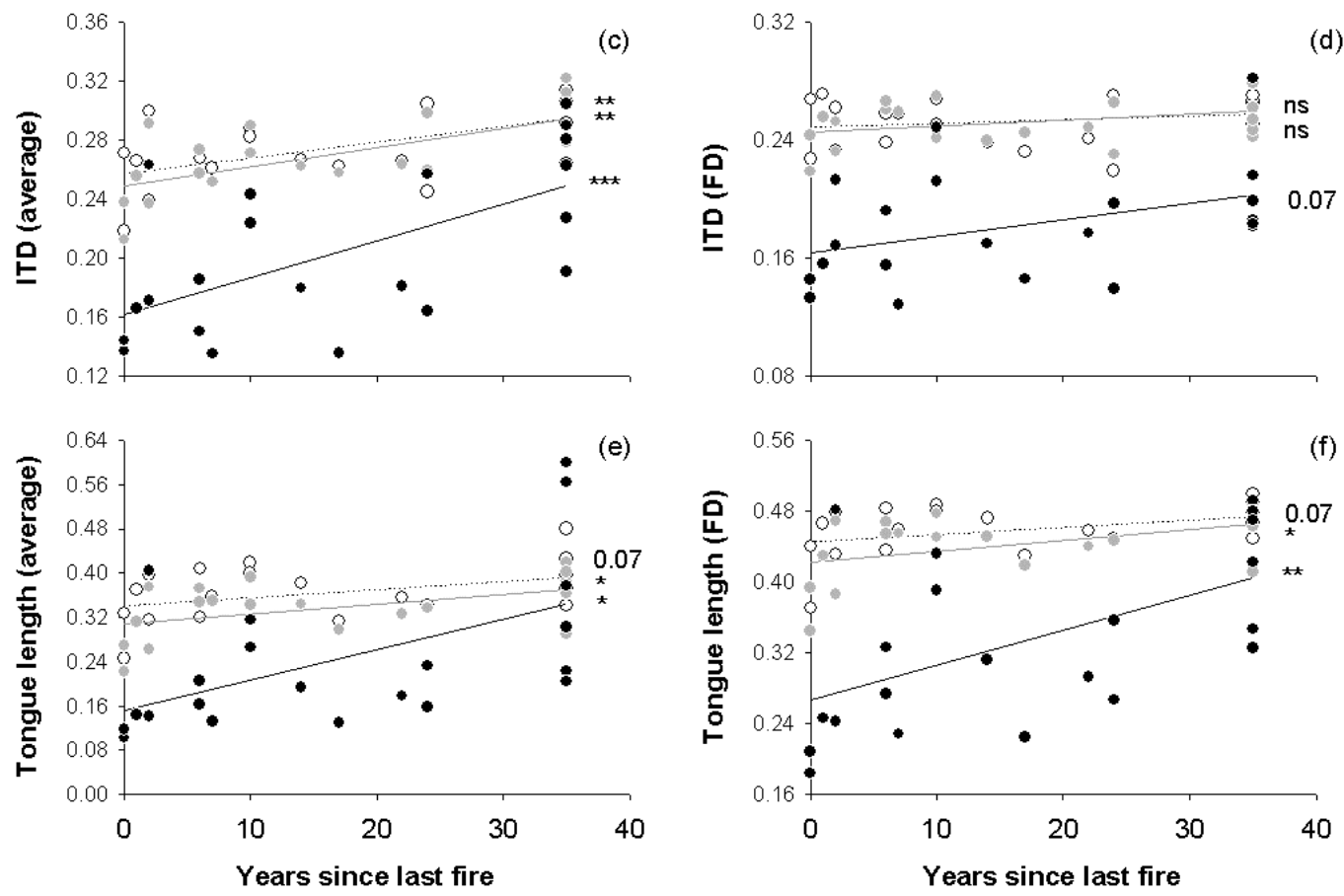

Figure 1. Response of different indices of functional trait composition (left: trait average; right functional diversity) to time elapsed since last fire. Example for three of the five traits used in the study (panel a and b for flying start; $\mathrm{c}$ and d for ITD; e and $\mathrm{f}$ for tongue length). All indices were calculated with different measures of species abundance. Asterisks indicate the level of significance $(* * *=p<0.001 ; * *=p<0.01 ; *=p<0.05 ; \mathrm{ns}=p>0.1)$. 

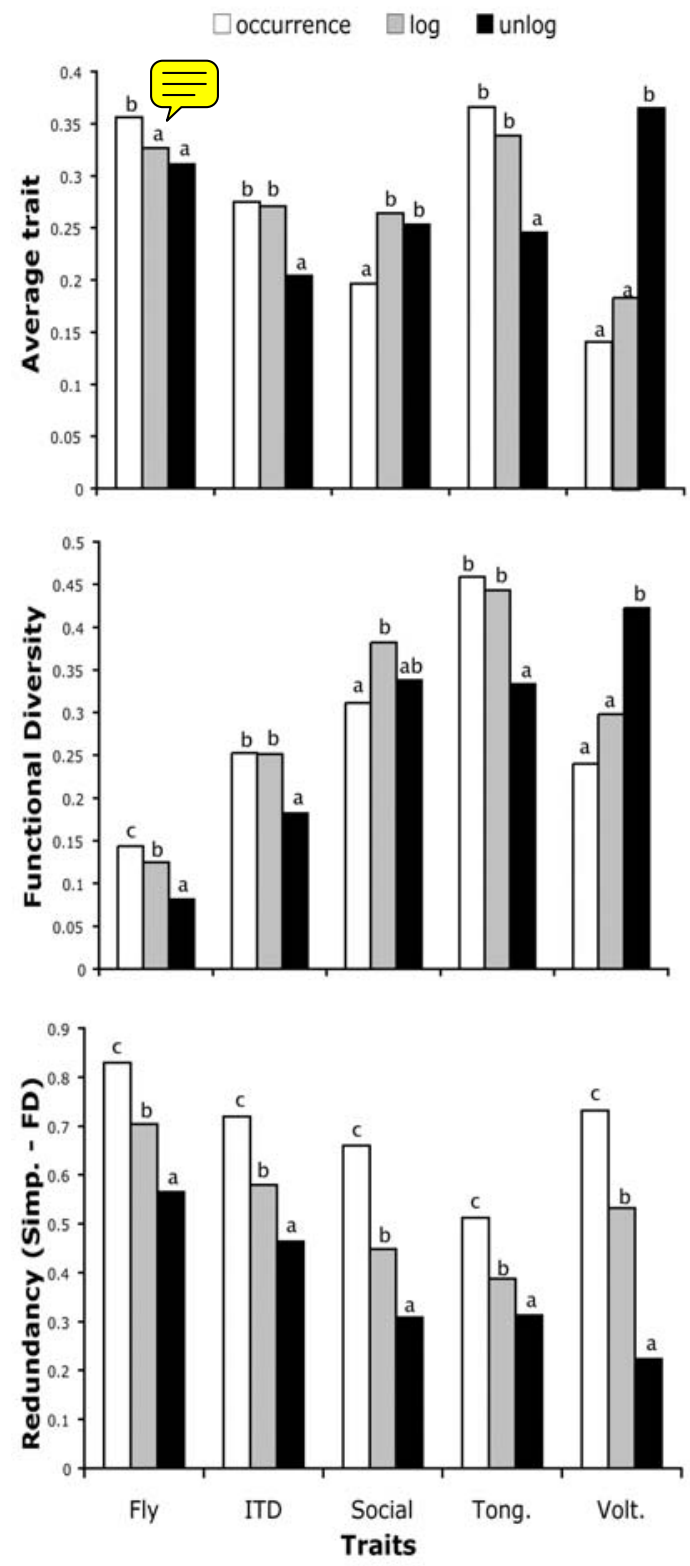

Figure 2. Mean values of the indices of trait composition (trait average, functional diversity and redundancy) for all study sites $(n=21)$. Different letters indicate significant differences within each trait (Tukey's test, $p<0.05$ ). Redundancy was calculated as the difference between the Simpson index of species diversity ('Simp') and functional diversity (FD) for a given community.

The mean values for the indices of trait composition changed over the whole data set when different measures of species abundance were used (Fig. 2). The values obtained for redundancy decreased markedly if more weight was given to species abundance (going from presence to unlog data; Fig. 2), and the values of the Simpson index of species diversity were also lower (not shown). The variation in trait averages and $\mathrm{FD}$, however, depended mostly on the traits considered.

\section{Discussion}

The indices of community functional composition are thought to be sensitive to the way species abundance is taken into account. This has been shown for trait average only in plant studies by Ackerly et al. (2002) and Cingolani et al. (2005). Our study demonstrates that similar patterns occur for indices of functional diversity and redundancy, also in invertebrate communities. Such observations imply, pragmatically, that in studies relying on these indices the methods used to estimate and consider species abundance should be stated clearly (Lepš et al. 2006). Also, extrapolations and comparisons among studies should be performed carefully (Magurran 2004, Petchey and Gaston 2006).

At the same time, the distinct responses of functional composition indices based on different species abundance measures (Fig. 1) can provide helpful insights into community assembly mechanisms (Cingolani et al. 2007). For example, if the response is more marked when considering species abundance, as shown by the average tongue length (Fig. 1), we could conclude that response of communities is driven mostly by changes in the relative abundance-dominance of species, rather then by replacements of species with different trait values. Conversely, the more marked response with measurements based on species occurrence or log-tranformed data (e.g., flying start FD, Fig. 1d) implies that the temporal change in a community's organization is based on a replacement of species with different traits with the most abundant-dominant traits remaining rather stable. Comparing the responses of trait averages and FD for a given trait can thus indicate whether the community reacts, for example, to disturbance in terms of the most abundant traits or in terms of a changed distribution of traits among species (Walker et al. 1999). Similarly, the correlations between the traits of dominant and rare species (comparison ' $v$ ' in Table 2) can indicate a system more or less buffered against environmental disturbances (as in Walker et al. 1999). If we assume that the distribution of traits in a community affects ecosystem processes and services (Diaz et al. 2007), such information can help identifying possible changes in biotic effects under environmental change scenarios.

According to our findings, the way species abundance is taken into account reflects to a greater or lesser extent the traits of particular classes of dominance within a community (van de Marrel 1979). In particular, the measure that attaches the greatest importance to differences in species abundance (unlog data) related mostly to the dominant species traits, while the measure that weighted species abundance lower (i.e., species occurrence) related more to rare species (Table 2). This observation is poten- 
tially useful for interpreting the distribution of common and rare species in the environment (Novotny and Basset 2000) and their responses to environmental changes (Walker et al. 1999, Kafer and Witte 2004). This should, however, be carefully translated into interpretations of ecological data. For example, unlog indices of functional composition reflect mainly the traits of the dominant species, but also to a much lesser extent, the traits of less dominant species (Table 2).

Finally, the particular data analyzed showed a general lack of correlation between trait average and functional diversity indices with species diversity indices (Table 3 ). These results indicate that the mechanisms that drive community functional assembly and maintain species coexistence do not necessarily overlap. In particular, the mechanisms that enhance the diversity of species do not necessarily support a functional differentiation (i.e., functional diversity) among those species (de Bello et al. 2006). This means also that it is probably unwise to use of species diversity indices as surrogates for functional diversity. Contrary to expectations, the use of species abundance in the calculation of functional diversity did not modify in a predictable way the value of the index (Petchey and Gaston 2006), but showed idiosyncratic effects for the different traits. Redundancy, partly due to its mathematical formulation, was more correlated to species diversity. This is why the measure that attaches more weight to species dominance (i.e., unlog) clearly reduced the values of redundancy (Table 3).

Overall, we conclude that (a) the indices of community functional composition are very sensitive to the way species abundance is taken into account (b) such sensitivity, however, can provide helpful insights into community assembly mechanisms; (c) the way species abundance is taken into account reflects to a greater or lesser extent the traits of particular classes of dominance within a community and (d) different indices of diversity reflect different components of biodiversity and are not necessarily related (e.g., species $v s$. functional diversity).

Acknowledgments. This research was funded by grants from the Swiss Federal Reseach Institute WSL, the Czech Ministry of Education (project LC 06073), the EU RUBICODE Project (VIth Framework Programme, EU036890) and the GDR utiliterres. We thank F. Amiet for the species identification, S. Roberts for information on traits, S. Dingwall for language revision and one anonymous referee for the precious suggestions.

\section{References}

Ackerly, D.D., Knight, C.A., Weiss, S.B., Barton, K. and Starmer, K.P. 2002. Leaf size, specific leaf area and microhabitat distribution of chaparral woody plants: contrasting patterns in species level and community level analyses. Oecologia 130:449-457.
Biesmeijer, J.C., Roberts, S.P.M., Reemer, M., Ohlemuller, R., Edwards, M., Peeters, T., Schaffers, A.P., Potts, S.G., Kleukers, R., Thomas, C.D., Settele, J. and Kunin, W.E. 2006. Parallel declines in pollinators and insect-pollinated plants in Britain and the Netherlands. Science 313: 351-354.

Botta-Dukát, Z. 2005. Rao's quadratic entropy as a measure of functional diversity based on multiple traits. Journal of Vegetation Science 16:533-540.

Cingolani, A.M., Posse, G. and Collantes, M.B. 2005. Plant functional traits, herbivore selectivity and response to sheep grazing in Patagonian steppe grasslands. Journal of Applied Ecology 42:50-59.

Cingolani, A.M., Cabido, M., Gurvich, D.E., Renison, D., and Diaz, S. 2007. Filtering processes in the assembly of plant communities: are species presence and abundance driven by the same traits? Journal of Vegetation Science 18: 911-920.

de Bello, F., Lepš, J. and Sebastià, M.T. 2006. Variations in species and functional plant diversity along climatic and grazing gradients. Ecography 29:801-810.

Diaz, S., Lavorel, S., Chapin, F.S., Tecco, P.A., Gurvich, D.E. and Grigulis, K. 2007. Functional diversity - at the crossroads between ecosystem functioning and environmental filters. In: Canadell, J., Pataki D.E. and Pitelka L.F. (eds.). Terrestrial Ecosystem in a Changing World. Springer, Berlin. pp. 81-91.

Garnier, E., Cortez, J., Billes, G., Navas, M.L., Roumet, C., Debussche, M., Laurent, G., Blanchard, A., Aubry, D., Bellmann, A., Neil, C. and Toussaint, J. P. 2004. Plant functional markers capture ecosystem properties during secondary succession. Ecology 85:2630-2637.

Kafer, J. and Witte, J.P.M. 2004. Cover-weighted averaging of indicator values in vegetation analyses. Journal of Vegetation Science 15:647-652.

Kremer, C., Williams, N.M., Aizen, M.A., Gemmill-Herren, B., LeBuhn, G., Minckley, R., Packer, L., Potts, G.S., Roulston, T., Steffan-Dewenter, I., Vázquez, D.P., Winfree, R., Adams, L., Crone, E.E., Greenleaf, S.S., Keitt, T.H., Klein, A-M., Regetz, J. and Ricketts, T.H. 2007. Pollination and other ecosystem services produced by mobile organisms: a conceptual framework for the effects of land-use change. Ecology Letters 10:299-314.

Lavorel, S., Grigulis, K., McIntyre, S., Garden, D., Willams, N., Dorrough, J., Berman, S., Quetier, F., Thebault, A. and Bonis, A. (2008) Assessing functional diversity in the field methodology matters! Functional Ecology (in press).

Lepš, J., de Bello, F., Lavorel, S. and Berman, S. 2006. Quantifying and interpreting functional diversity of natural communities: practical considerations matter. Preslia 78:481-501.

Lepš J. and Hadincová V. 1992. How reliable are our vegetation analyses? Journal Vegetation Science 3:119-124.

Magurran, A.E. 2004. Measuring Biological Diversity. Blackwell, Oxford.

Mason, N.W.H., Mouillot, D., Lee, W.G. and Wilson, J.B. 2005 Functional richness, functional evenness and functional divergence: the primary components of functional diversity. Oikos 111:112-118

Moretti, M., Obrist, M.K. and Duelli, P. 2004. Arthropod biodiversity after forest fires: winners and losers in the winter fire regime of the southern Alps. Ecography 27:173-186.

Moretti, M., Duelli, P. and Obrist, M.K. 2006. Biodiversity and resilience of arthropod communities after fire disturbance in temperate forests. Oecologia 149:312-327. 
Mühlenberg M. 1993. Freilandökologie. Quelle and Meyer, München.

Naeem, S. 1998. Species redundancy and ecosystem reliability. Conservation Biology 12:39-45.

Novotny, V. and Basset, Y. 2000. Rare species in communities of tropical insect herbivores: pondering the mystery of singletons. Oikos 89:564-572.

Petchey, O.L. and Gaston, K.J. 2006. Functional diversity: back to basics and looking forward. Ecology Letters 9:741-758.

Peterson, G., Allen, C.R. and Holling, C.S. 1998. Ecological resilience, biodiversity, and scale. Ecosystems 1:6-18.

Rao, C.R. 1982. Diversity and dissimilarity coefficients - a unified approach. Theoretical Population Biology 21: 24-43.

van der Maarel, E. 1979. Transformation of cover-abundance values in phytosociology and its effect on community similarity. Vegetatio 38:138-148.
Walker, B., Kinzig, A. and Langridge, J. 1999. Plant attribute diversity, resilience, and ecosystem function: The nature and significance of dominant and minor species. Ecosystems 2:95-113.

Whittaker, R.H. 1970. Communities and Ecosystems. MacMillan, New York.

Received June 12, 2007 Revised October 8, 2007 Accepted October 18, 2007

\section{Appendix}

Pearson correlations between pairs of measurements of trait community composition (either trait average or functional diversity). The file is downloadable from the Publisher's web site of this issue of Community Ecology at www.akademiai.com. 